Original Article

\title{
Association of Dietary Practices with Mental Health Problems Among Geriatrics
}

\author{
Maria Aslam ${ }^{1}$, Farwa Murtaza ${ }^{1}$, Sana Murtaza ${ }^{1}$, Natasha Azhar ${ }^{1}$, Nasir Abbas ${ }^{1}$, Samia Saleem ${ }^{1}$ and Fareena Manzoor ${ }^{1}$
}

${ }^{1}$ University Institute of Diet and Nutritional Sciences, The University of Lahore, Lahore, Pakistan

$\begin{array}{lr}\text { Keywords: } & \text { Geriatrics, } \\ \text { Dietary } & \text { Practices, } \\ \text { Malnutrition, Depression }\end{array}$

How to Cite:

Aslam, M. ., Murtaza, F. .,

Murtaza, S. ., Azhar, N. .,

Abbas, N. ., Saleem, S. ., \&

Manzoor, F. . (2020).

Association of Dietary

Practices with Mental Health

Problems among Geriatrics:

Dietary Practices with Mental

Health Problems among

Geriatrics. DIET FACTOR

(Journal of Nutritional

\&Amp; Food

Sciences), 1(01), 11-15.

https://doi.org/10.54393/df.v

1i01.6

Corresponding author:

Maria Aslam

University Institute of Diet and Nutritional Sciences,

Faculty of Allied Health

Sciences, The University of

Lahore, Lahore, Pakistan

maria.aslam@ahs.uol.edu.pk

Article History

Received: $21^{\text {st }}$ May 2020

Accepted: $25^{\text {th }}$ June 2020

Published: $30^{\text {th }}$ June 2020

\section{ABSTRACT}

Identification of elderly people dietary practices is the first step towards encouraging healthy diet in them. Proper diet, special care and supplementation are very necessary for effective physical or mental survival of older people with the age of 60-95 years. Objective: To find out the association of dietary practices with mental health problems among geriatrics. Methods: A Cross-sectional Study was operated to assess the dietary practices through pretested Questionnaire (MNA) on the basis of 24 hours' recall method among Older Adults. The study duration was 4 months and the technique was Non probability convenient sampling. The sample size was 290 older people out of which $48 \%$ were males and $52 \%$ were females aged between 60-95 years residing in different Old Age Homes of Lahore. The data were analyzed with SPSS version 21.0. The qualitative variables were reported using percentages and frequencies. Chisquare test was applied and p-value less than 0.05 was considered significant. Results: The results revealed that out of 290 respondents; 81(30\%) of them were skipping breakfast, $133(46 \%)$ were skipping lunch, 31(11\%) were skipping dinner. There were $115(40 \%)$ geriatrics which were suffering from depression, 101(35\%) were suffering from dementia, 29(10\%) were suffering from Insomnia, 45(15\%) had Dizziness/Irritability. Only 35(12\%) older adults who were taking Supplements. On daily basis, $198(68 \%)$ of elderly people were incorporating Chapatti/rice into their diet as the best source of energy, 61(21\%) respondents were preferring Milk/yogurt, 22(8\%) of older people were consuming fruit juices and salad, $8(3 \%)$ of older people were those whose daily food was Soup/porridge. Conclusions: The study concluded that most of the older adults were skipping their meals on daily basis and were suffering from depression, dementia, Insomnia, Dizziness/Irritability. They were less focusing on supplements. The elderly people were mostly consuming Chapatti/rice on daily basis from all of the food groups, they were observed in stressful situations during the meal, when most of the people had reduced their food, there were some who stopped eating. In both males and females, a trend of sweet and salty cravings was mostly seen.

\section{INTRODUCTION}

Older adults above the age of 65 are more vulnerable to nutritional deficiencies.1as aging comes with an accumulation of diseases and deficiencies some of which includes physical and mental retardation, emotional changes and depression decline, depressive symptoms, emotional variations, 2 beside socio-economic changes [1]. These factors may directly affect balance between needs and intake of nutrition [2]. Nutrition is an important element of health in the older population and affects the aging process whereas, malnutrition is increasing in elderly adults thus leading to improper functioning, decrease in bone mass, improper muscle functioning, delayed recovery from surgery, dys functioning of immune system, anemia, reduced psychological function, poor healing of wounds, increased hospital readmission rates, and deaths [3]. Through a survey conducted in Pakistan it was estimated that $5.53 \%$ of people lack proper nutrition and $42.10 \%$ were at risk in elderly age group. Improper nutrition was observed more in males $3.16 \%$ as compared to females $2.37 \%$ of the same age group. Malnutrition was significantly more common in upper age group eighty years and above [4]. During the past years, 
malnutrition is focused in older adults and is now regarded as a true geriatric syndrome characterized by multiple causes, some of identified symptoms along with weakness, ill health and poor outcome [5]. Older adults usually have loss of appetite and less energy expenditure with a decline in biological and physiological functions such as reduced lean body mass, hormonal level changes, imbalance fluid electrolyte, delay stomach emptying and loss of senses of smell and taste. Chronic diseases and psychological illness are also additional factors leading to malnutrition in older people. To treat patients at risk, assessment of nutritional status is very important [3]. Older adults above the age of 65 are more vulnerable to nutritional deficiencies [6]. Food intake over life span decreases gradually. In males food intake decreases by approximately $30 \%$ and in females its $20 \%$ [7]. The mini nutrition assessment has been a useful tool to identify frail patients [8]. Screening of older adults allows the intervention to be more successful [7]. Depression is the most common cause of loss or lack of appetite, both in older community and in the residents of old homes [9]. So when there is less intake of food it not only leads to weight loss but also loss of fat and loss of muscle and bone mass. This increases the tendency to fracture of bones, fall, or develop frailty [9]. In nutrition care assessment nutrition screening, assessment and intervention are important elements. Nutrition screening tells us about individuals who are lacking proper nutrition and who are at risk to determine if a detailed nutrition assessment is requited or not. Nutrition assessment provides the basis for a nutrition intervention [10]. Nutrition assessment lead to recommendations for improving nutrition status or some intervention such as changes in diet patterns, enteral or parenteral nutrition, or further any medical assessment or a recommendation for rescreening [11]. Eating and drinking decreases in the elderly and they eat sparingly, selectively or gradually as compared to adolescents. Behavior modification or nutritional knowledge of geriatrics about their eating habits is mandatory so they must incorporate diversity in their foodstuff. It will be beneficial to maintain excellent dietary stability in geriatrics [12]. In geriatrics due to loss of appetite with unhealthy or non-nutritious meal may cause inadequacy of micronutrients [3]. Eating habits that consist of modern standard or to take nutritious meal from basic 5 food groups but milk portion must be fat free is feasibly connected with improve physical and mental health of an elderly people [13].

The purpose of our study was to assess the nutritional status of elderly people in order to determine the daily requirements as this age group is more prone to physical and mental health disorders leading towards malnutrition. After knowing the inappropriate false dietary practices, awareness was provided regarding balanced diet through nutrition education.

\section{METHODS}

A Cross-sectional Study was operated to assess the dietary practices through pretested Questionnaire mini nutritional assessment (MNA) on the basis of 24 hours' recall method among Older Adults. The study duration was 4 months and the sample was selected through non probability convenient sampling technique. The sample size was 290 older people, out of which $48 \%$ were males and 52\% were females aged between 60-95 years residing in different Old Age Homes (Lahore). As Great Home (Bait-ul-Mal), Wapda Town, Happy Home for senior citizens, Azmat chowk Green Town, Darul Khalafa, Bhatta chowk Airport Road, Fraternity Old age home, Sue-e-Asal Road, Holistic healthcare Pak Arab Housing Scheme were chosen to collect relevant data. Tabulation was done through simple frequency and analysis method. Ethical approval was taken from the institutional review board (IRB) of The University of Lahore, Lahore. The data were analyzed with SPSS version 21.0. The qualitative variables were reported using percentages and frequencies. Chi-square test was applied and p-value less than 0.05 was considered significant.

\section{RESULTS}

Final analysis enlightened the dietary habits and concepts of old age people regarding different food and nutrients. Old age group is vulnerable group so if they are not provided with a balanced diet, they may face various mental and physical illnesses. Analysis revealed that $30 \%$ older adults were skipping their breakfast on regularly basis and did not had any awareness and knowledge about nutrition and they were seen lethargic, fatigued due to down energy level which was due to skipping breakfast. The chances of having a heart disease increase if breakfast is left out on daily basis because it's a major meal of a day.46\% respondents were skipping lunch, $11 \%$ older people were skipping dinner and there were only $15 \%$ elderly who were taking their all meals (Figure 1). 


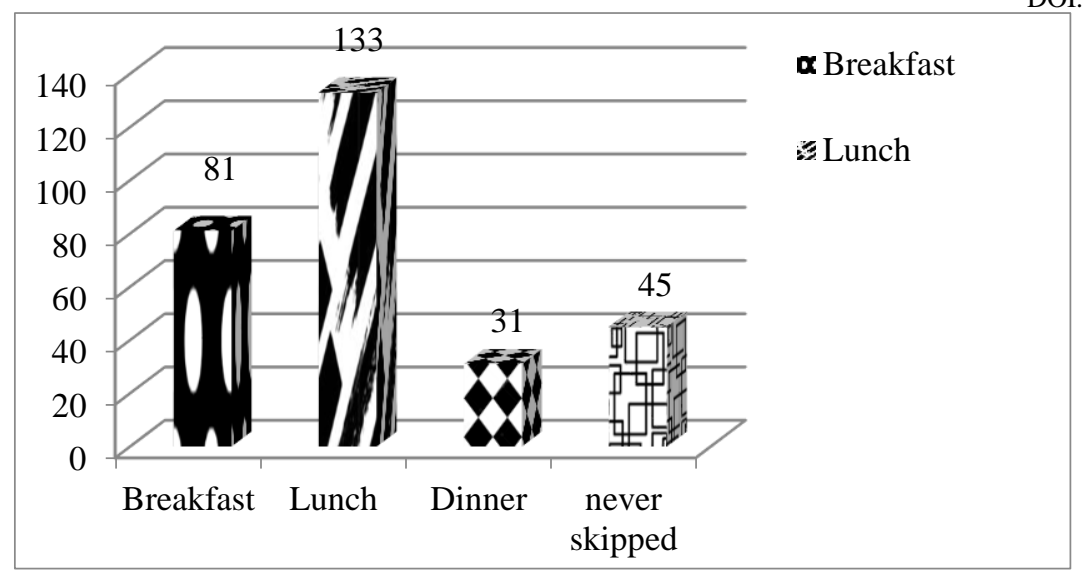

DOI: https://doi.org/10.54393/df.v1i01.6

Figure 1: Skipping meal practices in older adults

According to the results $40 \%$ of respondents were suffering from depression which led to their loss of appetite. Due to poor dietary habits or meal skipping on daily basis $35 \%$ of older people were suffering from dementia. $10 \%$ of older people were suffering from Insomnia and have poor nutrient intake. 15\% of respondents had Dizziness/Irritability (Figure 2).

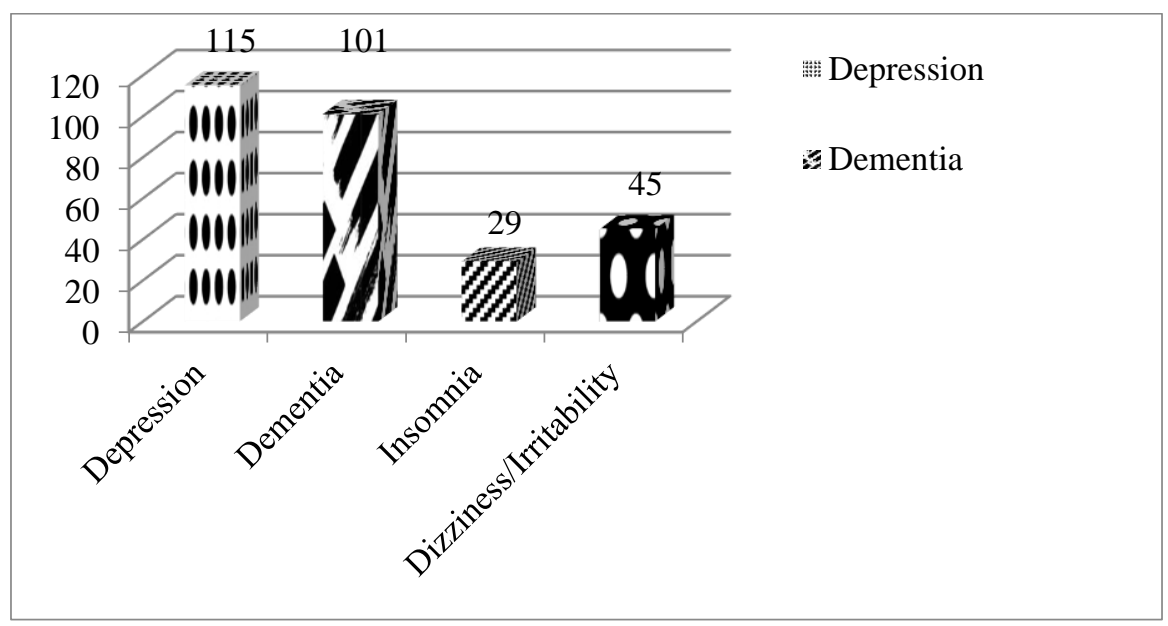

Figure 2: Emotional/Mental state directly linked to dietary patterns in older adults

According to results there were only $12 \%$ older adults who were taking Supplements along with their diets while $88 \%$ older were neglecting Supplements (Figure 3).

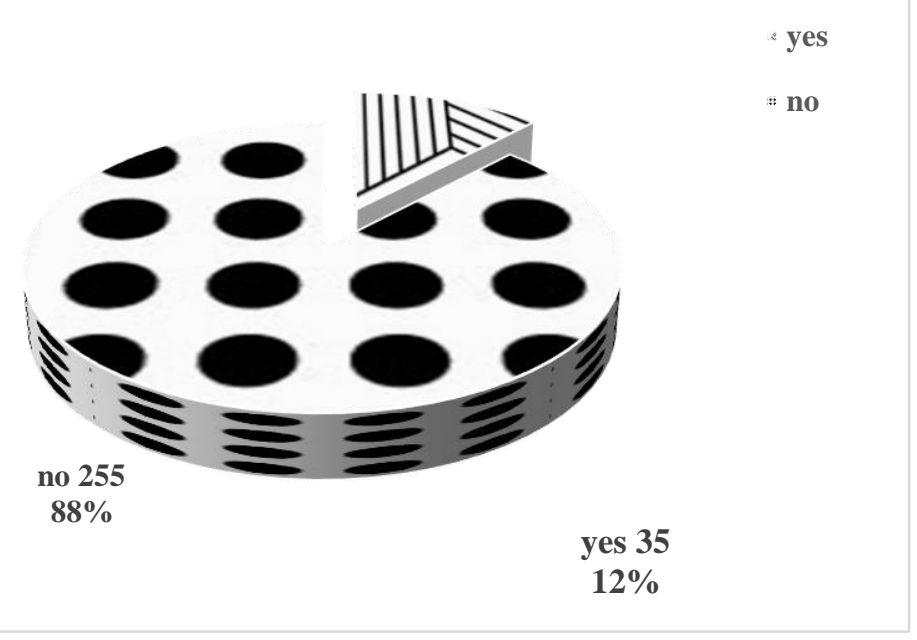

Figure 3: Supplementation practices in old age people 
According to the results $21 \%$ respondents preferred Milk/yogurt in their daily routine because they were aware from benefits of Milk/yogurt which they believed was an effective diet for their physical and mental health and strengthen their bones. Out of 21\% 13 respondents were those who were eating less,31 were eating routinely, 4 were eating more, 13 had stop off in case of stress situation. On daily basis, $68 \%$ of elderly people were incorporating Chapatti/rice into their diet as the best source of energy in which 43 respondents were those who were eating less, 70 were eating routinely, 19 were eating more and 66 had stop off in case of stress situation. $8 \%$ of older people were the ones who liked to consume fruit juices and salad on a daily basis in which 3 respondents were those who were eating less, 8 were eating routinely, 3 were eating more, 8 had stop off in case of stress situation.3\% of older people were those whose daily food was Soup/porridge in which 2 respondents were those who were eating less, 2 were eating routinely, 1 were eating more, 3 had stop off in case of stress situation. Only 1 respondent was taking other food except of all mention above or was eating routinely and had no effect of stress (Table 1). Moreover, there was insignificant association between daily food consumption and food consumption during stress, $\mathrm{p}=0.692$.

\begin{tabular}{|c|c|c|c|c|c|c|}
\hline \multirow{2}{*}{ Daily Foods } & \multicolumn{4}{|c|}{ Foods Consumption During Stress Situation } & \multirow[t]{2}{*}{ Total } & P-Value \\
\hline & Eat less & Eat routinely & Eat more & Stop off & & \multirow{7}{*}{0.692} \\
\hline Milk/yogurt & 13 & 31 & 4 & 13 & 61 & \\
\hline Chapatti/rice & 43 & 70 & 19 & 66 & $\begin{array}{r}19 \\
8\end{array}$ & \\
\hline Fruit juice/salad & 3 & 8 & 3 & 8 & 22 & \\
\hline Soup/porridge & 2 & 2 & 1 & 3 & 8 & \\
\hline Any other food & 0 & 1 & 0 & 0 & 1 & \\
\hline Total & 61 & 112 & 27 & 90 & $\begin{array}{r}29 \\
0\end{array}$ & \\
\hline
\end{tabular}

Table 1: Association between Foods consumption on Daily Basis and food consumption during stress among older people

Analysis revealed that $52 \%$ were old females in which 5 had sour food cravings, 67 had sweet food cravings, 63 had salty food cravings and 16 had bitter food cravings. $48 \%$ were old males in which 4 had sour food cravings, 69 had sweet food cravings, 41 had salty food cravings and 25 had bitter food cravings, (Table 2). There was insignificant association between gender and food cravings in older adults, $\mathrm{p}=0.099$.

\begin{tabular}{|l|l|l|l|l|l|l|}
\hline \multirow{2}{*}{ Gender } & \multicolumn{3}{|c|}{ Specific Food Cravings In Older Adults } & \multirow{2}{*}{ Total } & P-Value \\
\cline { 2 - 6 } & Sour & Sweet & Salty & Bitter & & \\
\cline { 1 - 6 } Female & 5 & 67 & 63 & 16 & 151 & \multirow{2}{*}{0.099} \\
\hline Male & 4 & 69 & 41 & 25 & 139 & \\
\hline Total & 9 & 136 & 104 & 41 & 290 & \\
\hline
\end{tabular}

Table 2: Gender based association of food cravings in older adults

\section{DISCUSSION}

The results of the current study showed that $51.7 \%$ of the individual usually take meal alone and $39 \%$ are those who usually skip meal on daily basis. Similar results were also recorded by Tani Y et al., in his study he observed $44 \%$ of the individual exclusively ate alone and of those who ate alone exclusively were 3.74 times more likely to skip meals [14]. In another study by Boulos $\mathrm{C}$ et al., in Lebanes in which data was recorded to assess the nutritional status of individuals. Depression was one of the factor in assessment tool on which conclusion was made that depression causes loss of appetite in older adults resulting in poor health outcomes [15]. Engel $\mathrm{JH}$ et al., in his study also stated that toughness, depression and emotional well-being all are significantly associated with appetite and these associations directly effect on mental health [16]. The results of the current study showed that $75 \%$ older adults have mental disorders similar results were found to a study conducted in 2015 by Prince MJ, 23\% of the total global burden of disease is attributable to disorders in people aged 60 years and older. The leading contributors to disease burden in older people are cardiovascular diseases $30.3 \%$ of the total 
burden in people aged 60 years and older, chronic respiratory disorders $9.5 \%$, neoplasms $15.1 \%$, neurological and mental disorders $6.6 \%$ and musculoskeletal diseases $7.5 \%$ leading to an increased proportion of morbidity and mortality in older people [17]. The current study revealed that depression in older adults affect their dietary patterns. Similar results were found by Lai JS et al., in 2013 conducted a observational study to evaluate the dietary patterns and depression among adults. They suggested that high intakes of fruit, vegetables, fish, and whole grains may be associated with a reduced depression risk [18]. According to present study $10 \%$ of older people were suffering from Insomnia and have poor nutrient intake. A study conducted by Zadeh SS and Begum K revealed same results that approximately $60 \%$ of the participants were insomniacs'. The study concluded that people with insomnia consumed significantly lesser quantities of nutrients as compared to normal sleepers [19]. Current findings also revealed that among elderly the main energy source is from cereals and grain group whereas other nutrients from milk/meat group or fruits/vegetable group are overlooked. Johnston $\mathrm{R}$ et al., in his study founded the same results in which he noticed that total calorie intake increases significantly among older adults with decrease in total fats consumption and greatly decline in other food groups neglecting nutrients requirement [20]. According to present study there is very less intake of supplementations among elderly. In this age group nutrients requirement are difficult to be fulfilled through diet as in this age group there are many consequences beside physical decline. Nieuwenhuizen WF et al., in his study concluded same that there are many factors affecting nutritional intake of elderly people but it could be compensated by adding frequent meals, small snacks, fortification of meal, by adding variety or oral nutrition supplements can be more effective to meet the daily need [12].

\section{CONCLUSIONS}

Based on the results of the current study with the growing age there are many physical and mental changes in health status of elderly adults, high rate of depression and dementia leading towards poor appetite and less intake of food, usual skipping of meals or taking meals individually with approximately no supplementation. Poor dietary habits can cause reduced food intake which may lead older people towards malnutrition and cognitive impairment.

\section{REFERENCES}

1. Fávaro-Moreira NC, Krausch-Hofmann S, Matthys C, Vereecken C, Vanhauwaert E, Declercq A, Bekkering GE, Duyck J Risk factors for malnutrition in older adults: a systematic review of the literature based on longitudinal data. Adv. Nutr., 2016. 7(3), 507-522. https://doi.org/10.3945/an.115.011254

2. Lonterman-Monasch S, de Vries OJ, Danner SA, Kramer MH, Muller M. Prevalence and determinants for malnutrition in geriatric outpatients. Clin. Nutr., 2013. 32(6), 1007-1011. https://doi.org/10.1016/j.clnu.2013.05.007

3. Ahmed T, Haboubi N. Assessment and management of nutrition in older people and its importance to health. Clin. Interven. Aging, 2010. 5, 207. doi: 10.2147/cia.s9664

4. Ghani A, Hussain S, Zubair M. Assessment of nutritional status of geriatric population in Sargodha city. Int. J. med. Appl. Hlth. 2013. 1(1).

5. Volkert D. Malnutrition in older adults-urgent need for action: a plea for improving the nutritional situation of older adults. Gerontol., 2013. 59(4), 328-333. https://doi.org/10.1159/000346142

6. De Morais C, Oliveira B, Afonso C, Lumbers M, Raats M, De Almeida MD. Nutritional risk of European elderly. Europ. J Clin. Nutr., 2013. 67(11), 1215-1219. https://doi.org/10.1038/ejcn.2013.175

7. Morley JE. Anorexia, weight loss, and frailty. J. Am. Med. Directors Assoc., 2010. 11(4), 225-228. https://doi.org/10.1016/j.jamda.2010.02.005

8. Muscaritoli M, Anker SD, Argiles J, Aversa Z, Bauer JM, Biolo G, Boirie Y, Bosaeus I, Cederholm T, Costelli P, Fearon KC. Consensus definition of sarcopenia, cachexia and pre-cachexia: joint document elaborated by Special Interest Groups (SIG) "cachexia-anorexia in chronic wasting diseases" and "nutrition in geriatrics". Clin. Nutr., 2010. 29(2), 154-159. https://doi.org/10.1016/j.clnu.2009.12.004

9. Morley JE. Depression in nursing home residents. J. Am. Med. Directors Assoc., 2010. 11(5), 301-303. https://doi.org/10.1016/j.jamda.2010.03.012

10. Mueller C, Compher C, Ellen DM, American Society for Parenteral and Enteral Nutrition (ASPEN) Board of Directors. ASPEN clinical guidelines: nutrition screening, assessment, and intervention in adults. J. Parent. Enteral Nutr., 2011. 35(1), 16-24. Doi: 10.1177/0148607110389335. 
11. Ukleja A, Freeman KL, Gilbert K, Kochevar M, Kraft MD, Russell MK, Shuster MH, Task Force on Standards for Nutrition Support: Adult Hospitalized Patients, and the American Society for Parenteral and Enteral Nutrition Board of Directors. Standards for nutrition support: adult hospitalized patients. Nutr. Clin. Pract., 2018. 33(6), 906-920. https://doi.org/10.1002/ncp.10204

12. Nieuwenhuizen WF, Weenen H, Rigby P, Hetherington MM. Older adults and patients in need of nutritional support: review of current treatment options and factors influencing nutritional intake. Clin. Nutr., 2010. 29(2), 160-169. https://doi.org/10.1016/j.clnu.2009.09.003

13. Anderson AL, Harris TB, Tylavsky FA, Perry SE, Houston DK, Hue TF, Strotmeyer ES, Sahyoun NR, Study HA. Dietary patterns and survival of older adults. J. Am. Dietet. Assoc., 2011. 111(1), 84-91. https://doi.org/10.1016/j.jada.2010.10.012

14. Tani Y, Kondo N, Takagi D, Saito M, Hikichi H, Ojima T, Kondo K. Combined effects of eating alone and living alone on unhealthy dietary behaviors, obesity and underweight in older Japanese adults: Results of the JAGES. Appetit., 2015. 95, 1-8. https://doi.org/10.1016/j.appet.2015.06.005

15. Boulos C, Salameh P, Barberger-Gateau P. Malnutrition and frailty in community dwelling older adults living in a rural setting. Clin. Nutr., 2016. 35(1), 138-143. https://doi.org/10.1016/j.clnu.2015.01.008

16. Engel JH, Siewerdt F, Jackson R, Akobundu U, Wait C, Sahyoun N. Hardiness, depression, and emotional wellbeing and their association with appetite in older adults. J. Am. Geriat. Societ., 2011. 59(3), 482-487. https://doi.org/10.1111/j.1532-5415.2010.03274.x

17. Prince MJ, Wu F, Guo Y, Robledo LM, O'Donnell M, Sullivan R, Yusuf S. The burden of disease in older people and implications for health policy and practice. The Lancet, 2015. 385(9967), 549-562. https://doi.org/10.1016/S0140-6736(14)61347-7

18. Lai JS, Hiles S, Bisquera A, Hure AJ, McEvoy M, Attia J. A systematic review and meta-analysis of dietary patterns and depression in community-dwelling adults. Am. J. Clin. Nutr., 2014. 99(1), 181-197. https://doi.org/10.3945/ajcn.113.069880

19. Zadeh SS, Begum K. Comparison of nutrient intake by sleep status in selected adults in Mysore, India. Nutr. Res. Prac., 2011. 5(3), 230-235. https://doi.org/10.4162/nrp.2011.5.3.230

20. Johnston R, Poti JM, Popkin BM. Eating and aging: Trends in dietary intake among older Americans from 19772010. J. Nutr. Hlth. Aging, 2014. 18(3), 234-242. https://doi.org/10.1007/s12603-013-0387-y. 